\title{
Efficacy of Pelvic Floor Muscle Training and Cough- suppression Therapy to Reduce Urinary Incontinence in Women With Chronic Obstructive Pulmonary Disease - a Randomised Controlled Study
}

Stacey Haukeland-Parker ( $\square$ stacey.haukeland.parker@so-hf.no)

Sykehuset Østfold https://orcid.org/0000-0003-1620-9848

\section{Bente Frisk}

Western Norway University of Applied Sciences: Hogskulen pa Vestlandet

\section{Martijn A Spruit}

Ciro

\section{Signe Nilssen Stafne}

NTNU Faculty of Medicine: Norges Teknisk-Naturvitenskapelige Universitet Fakultet for Medisin og Helsevitenskap

\section{Hege Hølmo Johannessen}

Østfold University College Faculty of Health and Welfare: Hogskolen i Ostfold Avdeling for helse og velferd

\section{Research Article}

Keywords: Chronic obstructive pulmonary disease, urinary incontinence, pelvic floor muscle training, cough-suppression therapy

Posted Date: October 20th, 2021

DOl: https://doi.org/10.21203/rs.3.rs-826466/v1

License: (c) (1) This work is licensed under a Creative Commons Attribution 4.0 International License. Read Full License 


\section{Abstract}

\section{Background}

Little is known regarding treatment of urinary incontinence $(\mathrm{UI})$ in women with chronic obstructive pulmonary disease (COPD). The aim of the study was to explore the efficacy of pelvic floor muscle training (PFMT) or cough-suppression techniques (CST) on Ul in women with COPD.

\section{Methods}

A three armed, two centred, single blinded, randomised controlled study was performed. Subjects were randomised to a) PFMT for 16 weeks, b) 2-3 educational sessions in CST, or c) written information only. All participants completed questionnaires about $\mathrm{UI}$, cough symptoms and health status, and underwent clinical examinations to evaluate strength of the pelvic floor muscles and exercise capacity. Daily physical activity levels were measured using an activity monitor, and lung function with spirometry. With a significance level of $5 \%$ and an $80 \%$ chance of detecting a significant difference between groups of 2.5 points on the ICIQ UI SF score, our sample size calculation showed that a total of 78 women, 26 in each group, was required to complete the study.

Results

During the period 2016 to 2018, 95 women were invited to the study. A total of 42 were recruited, 3 were excluded and 10 (24\%) dropped out during the follow-up period. Mean ICIQ-UI SF total baseline score was 9.6 (range: 1-17) and 7.0 (range: 0-16) at follow up. Significant changes in subjective Ul as measured with the ICIQ-UI SF questionnaire were seen in the PFMT group $(p=0.03)$ and control group $(p=0.02)$, but not in the CST group $(p=0.46)$.

\section{Conclusion}

ue to the low number of available participants and recruitment difficulties including practical issues such as travel distance, lack of interest, poor state of health and high number of comorbidities, our results are inconclusive. However, reduced subjective UI was observed in the PFMT and control groups with a trend towards best effect in the PFMT group. Screening for UI is advisable in all women with COPD to be able to identify and treat these women to reduce symptom burden and improve quality of life. Future studies should focus on barriers to recruitment as well as randomised controlled studies with larger sample sizes.

Trial registration

The study is registered on ClinicalTrials.gov (NCT02614105).

\section{Background}


Urinary incontinence $(\mathrm{UI})$ is any involuntary loss of urine. Prevalence increases with age and women are more exposed than men due to pregnancy, childbirth and menopause (1-4). Stress urinary incontinence (SUI) is associated with activities involving increased intra-abdominal pressures such as physical exertion, sneezing, coughing or laughing (5). Respiratory disease is considered a risk factor for $\mathrm{UI}$ due to coughing and dyspnoea (6) which increase pressure on the bladder and may lead to leakage if the pelvic floor muscles (PFM) are weak. In addition, regular coughing may further weaken ligaments in the pelvic floor resulting in UI (7). Dyspnoea and chronic cough are common symptoms in patients with chronic obstructive pulmonary disease (COPD) (8) and a significant number of women with COPD also suffer from UI $(6,9,10)$. Prevalence of SUI in the general population of women is reported to be between 25$40 \%$, whereas approximately $50 \%$ of women with COPD suffer from UI with SUI being the most common form, presumably due to coughing (9). Ul is associated with lower health-related quality of life (HRQL) in people with COPD, especially amongst women (11).

Although $\mathrm{Ul}$ is not a life-threatening condition, it is common and can have numerous negative psychological, social, and economical effects. Women with $\mathrm{UI}$ in the general population have higher levels of depression, anxiety and stress, poor sleep quality and significantly lower HRQL (12-14). Additionally, long term UI may result in absence from work, increased healthcare costs, social isolation and physical inactivity $(12,14,15)$. Inactivity is common from the early stages of the COPD due to dyspnoea $(16,17)$. Furthermore, inactivity is associated with risk of hospital admissions $(18)$ and is a strong predictor for mortality (19). The combination of UI and COPD may therefore result in a double risk factor in terms of exercise avoidance and the subsequent negative consequences of inactivity.

The current evidence regarding treatment options for women with COPD and coexisting $\mathrm{UI}$ is poor. Pelvic floor muscle training (PFMT) is well documented for reducing SUI in other populations (4), but only one small study has explored the effect of PFMT in a COPD population. However, the study included few participants, no controls, and PFMT was given in combination with other interventions (20). Coughsuppression therapy (CST) has been demonstrated to positively benefit patients with refractory cough in terms of symptoms and HRQL (21), and may potentially be effective in reducing cough and subsequently SUI. However, there is no current evidence for CST amongst people with COPD and UI. Therefore, the aim of this study was to explore the effect of PFMT and CST in reducing UI amongst women with COPD. We hypothesised that PFMT and/or CST could reduce subjective $\mathrm{Ul}$ as compared to no active treatment/standard care.

\section{Methods}

\section{Study design}

A three armed, two-centered, single-blinded, randomised controlled study was performed. Participants were randomised to one of three groups receiving either PFMT, CST or written information only.

\section{Subjects}


Participants were recruited from physiotherapy departments or pulmonary rehabilitation courses at two hospitals and at local physiotherapy clinics in two separate health regions in Norway. Women aged $\geq 18$ years with clinically stable COPD in GOLD stages I-IV were included (22). Further inclusion criteria were self-reported $\mathrm{UI}$ and the ability to perform a voluntary pelvic floor muscle contraction (VPFMC). Exclusion criteria were unstable COPD, $>4$ hospital admissions due to COPD during the last 12 months, neurological conditions, and gynaecological surgery.

Randomisation was performed using an internet-based, computerized procedure and was stratified on hospital affinity. Clinicians involved in the clinical assessments were blinded to, and had no influence on, the randomisation procedure. Due to the nature of the interventions, participants and physiotherapists were not blind to group allocation.

\section{Interventions}

\section{PFMT group}

The PFMT program was based on the principles for increasing PFM strength (23). Participants received group exercise sessions (one hour) at a local physiotherapy clinic or physiotherapy department at the hospitals once weekly for 16 weeks with guidance from an experienced physiotherapist. The group exercise sessions focused on PFMT, relaxation and breathing techniques. In addition, the participants received a PFMT program for daily home use $(24)$ and written information about PFMT $(25,26)$. Participants were encouraged to perform three sets of 8-12 close to maximum VPFMC daily and to hold the contraction for more than three seconds. Progression of the PFMT included holding the VPFMC for up to ten seconds, adding three fast contractions at the end of the VPFMC, and progressively more challenging starting positions.

\section{CST group}

Participants attended one group education session (one hour), 1-2 individual sessions (30-60 minutes) tailored to individual needs by an experienced cardiorespiratory physiotherapist, and received CST exercises and written information for home use. Sessions included general information about CST and advice about how to distinguish between unproductive and productive cough to avoid unnecessary coughing.

\section{Control group}

Participants received instruction on correct VPFMC at clinical assessment (to allow for assessment) and brief written information about PFMT and CST, but no other form of regular follow-up or intervention. PFMT or CST was allowed due to ethical considerations, but not encouraged.

\section{Materials}

\section{Outcome measures}


Frequency, volume and type of $\mathrm{Ul}$ as well as the overall impact on HRQL was measured using the International Consultation on Incontinence Questionnaire - Urinary Incontinence Short Form (ICIQ-UI SF). ICIQ-UI SF has demonstrated good validity and reliability (27) and is sensitive to change after intervention (28). Scores range from 0 to 21 points, with a higher score indicating worse severity.

\section{Daily physical activity}

Daily physical activity and steps per day were monitored for one week ( 24 hours per day) before and after the intervention period using a SenseWear armband monitor (BodyMedia Inc., Pittsburgh PA). SenseWear has been shown to have good reliability, validity and compliance amongst people with $\operatorname{COPD}(29,30)$.

\section{Functional exercise capacity}

The six-minute walk test (6MWT) was used to measure functional exercise capacity, expressed as the distance walked in six minutes (6MWD). The 6MWT is a valid and reliable outcome measure for assessing exercise tolerance in the COPD population $(31,32)$. The test was performed indoors by experienced physiotherapists along a 30-meter straight, flat corridor according to guidelines (32). A practice test was performed to exclude any learning effects.

\section{Cough}

Physical, psychological and social factors related to cough were measured using the Norwegian version of the Leicester Cough Questionnaire $(33,34)$. The questionnaire includes 19 items with a 7-point Likert scale ranging from no symptoms ("Not at all") to debilitating symptoms ("All the time"). Total scores vary from 3 to 21 points with a higher score indicating less symptoms and better HRQL.

\section{Health status}

The COPD Assessment Test (CAT) is a disease-specific, reliable and validated questionnaire measuring health status in COPD (35). Scores range from 0 to 40 points, with a higher score indicating higher symptom burden.

\section{Pelvic floor muscle strength}

Participants underwent clinical examination and evaluation of VPFMC function using vaginal palpation and the International Continence Society (ICS) Score (36). The scale ranges from no active muscular contraction ("1"), reduced function ("2"), normal function ("3") and spastic ("4"). All participants scored $\geq$ 2 on the ICS score as according to our inclusion criteria.

\section{Lung function measurements}

Post bronchodilator spirometry was conducted on a Master Screen PFT system (CareFusion, Germany). Forced expiratory volume in 1 second $\left(\mathrm{FEV}_{1}\right)$ and forced vital capacity (FVC) were taken as the highest 
value from at least three satisfactory manoeuvres and $\mathrm{FEV}_{1} / \mathrm{FVC}$ ratio according to Norwegian reference values (37) were used.

In addition, relevant background information such as age, smoking history, parity, mode of child delivery, and menopause were collected.

\section{Procedure}

Statistics

\section{Sample size estimation}

The primary outcome variable was mean ICIQ-UI SF score at post-intervention and a difference in mean ICIQ-UI SF score of at least 2 points was considered to be of clinical interest. A power calculation was performed in the hope to perform a full RCT. Based on similar studies and clinical experience, we assumed that a reduction in ICIQ-UI SF scores would be $\geq 60 \%$ within the PFMT group and $\geq 30 \%$ within the CST and control groups due to placebo effect and being instructed on VPFMC at initial assessment. Based on results from published studies on $\mathrm{UI}(3)$, we assumed that the mean improvement in the ICIQ-UI SF scores in each of the three groups would be 2.5 points. We aimed for a probability of $80 \%$ to identify differences between the groups. With a significance level of $5 \%$, the calculation showed that a minimum of 26 participants were required in each group (total 78 participants).

Descriptive statistics were used to characterise the study population: mean, standard deviation (SD), median, percent and interquartile range as appropriate. Paired samples t-test were used to examine the effect of the PFMT and CST treatments in reducing UI and change in physical capacity and health status. The association between ICIQ-UI SF, age, UI duration, VPFMC, functional exercise capacity and health status were examined using Pearson's product-moment correlation coefficient. Between group analyses were not performed due to the low number of participants.

Estimated regression coefficients are presented with 95\% confidence interval and p-values.

Statistical significance level was set at $5 \%$. All statistical analyses were performed with the SPSS Statistics 26 (SPSS Inc. Chicago, IL, USA).

\section{Results}

\section{Baseline characteristics}

Participants were recruited during the period 2016 and 2018. In total, 95 women were invited to participate in the study and 42 women were recruited (Fig. 1). Reasons for women declining to participate are shown in Fig. 1. Three participants were excluded after recruitment and 10 dropped out. Mean age $( \pm$ $\mathrm{SD})$ was $66.4( \pm 7.9)$ years and mean $\mathrm{FEV}_{1}$ was $52.7 \%$ predicted $( \pm 16.8)$. According to GOLD stages, $15 \%$ 
had mild, $39 \%$ moderate, $33 \%$ severe and $8 \%$ very severe COPD. GOLD stages were missing for two patients (5\%) due to lack of spirometry measures prior to recruitment. Mean ICIQ-UI SF score was 9.6 ( \pm 4.3) points suggesting moderate UI severity. VPFMC was weak in 16 women (55\%), normal in eight (28\%) and spastic in five $(17 \%)$ at baseline. The overall mean CAT score was $22.1( \pm 6.8)$ points indicating high COPD symptom burden. There were no statistically significant differences at baseline between the completers and non-completers or intervention groups regarding $\mathrm{Ul}$ severity and duration, VPFMC, physical capacity, lung function, cough symptoms and health status (Table 1). The total scores on the ICIQ-UI SF had a statistically significant correlation with UI duration $(r=0.59, p=0.01)$, but there was no correlation with the other variables (Table 2). Compliance and dropout were similar in the three groups (Fig. 1). The interventions were well tolerated and no adverse events were registered. 
Table 1

Baseline characteristics of study participants $(n=39)$

\begin{tabular}{|llllll|}
\hline Baseline & $\begin{array}{l}\text { All } \\
\text { participants }\end{array}$ & $\begin{array}{l}\text { PFMT } \\
\text { group } \\
\mathbf{n}=39\end{array}$ & $\begin{array}{l}\text { CST group } \\
\mathbf{n}=7\end{array}$ & $\begin{array}{l}\text { Control } \\
\text { group }\end{array}$ & $\begin{array}{l}\text { Non- } \\
\text { completers }\end{array}$ \\
\hline Age (years) & $66.4 \pm 7.9$ & $67.6 \pm 5.5$ & $67.9 \pm 5.4$ & $63.9 \pm 12.3$ & $66.3 \pm 6.9$ \\
\hline Current smokers, & $12(31)$ & $1(14)$ & $4(33)$ & $5(50)$ & $2(20)$ \\
n (\%) & & & & & $\mathbf{n = 1 0}$ \\
\hline Nullipara, n (\%) & $5(13)$ & $0(0)$ & $1(8)$ & $3(30)$ & $1(10)$ \\
\hline Parity & $2.0 \pm 1.1$ & $2.3 \pm 0.5$ & $2.2 \pm 0.9$ & $1.8 \pm 1.7$ & $1.8 \pm 0.9$ \\
\hline UI duration (years) & $10.8 \pm 11.5$ & $9.7 \pm 10.9$ & $9.4 \pm 11.9$ & $10.3 \pm 11.7$ & $13.2 \pm 12.9$ \\
\hline FEV (\% pred.) & $52.7 \pm 16.8$ & $50.9 \pm 12.8$ & $52.0 \pm 17.1$ & $57.9 \pm 18.9$ & $49.0 \pm 18.2$ \\
\hline FVC (\% pred.) & $78.9 \pm 14.7$ & $82.7 \pm 10.4$ & $75.2 \pm 16.5$ & $85.2 \pm 16.5$ & $75.1 \pm 14.2$ \\
\hline GOLD class, n (\%) & $6(15)$ & $1(14)$ & $3(25)$ & $2(20)$ & $0(0)$ \\
\hline I & $15(39)$ & $2(29)$ & $2(17)$ & $5(50)$ & $6(60)$ \\
\hline II & $13(33)$ & $3(43)$ & $6(50)$ & $3(30)$ & $1(10)$ \\
\hline III & $3(8)$ & $1(14)$ & $0(0)$ & $0(0)$ & $2(20)$ \\
\hline IV & $2(5)$ & $0(0)$ & $1(8)$ & $0(0)$ & $1(10)$ \\
\hline Missing & & & & & \\
\hline 6MWD (m) & $383 \pm 112$ & $382 \pm 97$ & $375 \pm 160$ & $388 \pm 88$ & $387 \pm 84$ \\
\hline Steps/day & $3563 \pm 3063$ & $3565 \pm$ & $2439 \pm$ & $4449 \pm 3434$ & $4118 \pm 4374$ \\
\hline CAT total score & $22.1 \pm 6.8$ & $24.1 \pm 5.7$ & $20.6 \pm 6.8$ & $25.5 \pm 5.7$ & $18.9 \pm 7.2$ \\
\hline ICIQ-UI SF total score & $9.6 \pm 4.3$ & $8.9 \pm 4.3$ & $7.3 \pm 4.6$ & $11.4 \pm 2.8$ & $11.1 \pm 4.3$ \\
\hline
\end{tabular}

Data are presented as mean \pm SD otherwise stated. PFMT: Pelvic Floor Muscle Training; CST: CoughSuppression

Therapy; $\mathrm{FEV}_{1}$ : forced expiratory volume in one second; FVC: Forced vital capacity; GOLD: Global Initiative for Chronic

Obstructive Lung Disease; 6MWD; six-minute walk distance; CAT: COPD Assessment Test; ICIQ-UI SF: International Consultation on Incontinence Questionnaire - Urinary Incontinence Short Form ; LCQ: Leicester Cough Questionnaire; IQR: interquartile range. 


\begin{tabular}{|c|c|c|c|c|c|}
\hline Baseline & $\begin{array}{l}\text { All } \\
\text { participants } \\
n=39\end{array}$ & $\begin{array}{l}\text { PFMT } \\
\text { group } \\
n=7\end{array}$ & $\begin{array}{l}\text { CST group } \\
\mathrm{n}=12\end{array}$ & $\begin{array}{l}\text { Control } \\
\text { group } \\
n=10\end{array}$ & $\begin{array}{l}\begin{array}{l}\text { Non- } \\
\text { completers }\end{array} \\
n=10\end{array}$ \\
\hline \multirow{2}{*}{$\begin{array}{l}\text { LCQ total median } \\
\text { (IQR) }\end{array}$} & 16.0 & 15.0 & 15.0 & 17.0 & 18.0 \\
\hline & $(14.0-18.8)$ & $\begin{array}{l}(14.0- \\
20.0)\end{array}$ & $\begin{array}{l}(12.8- \\
18.0)\end{array}$ & $(13.0-18.2)$ & $(15.5-20.5)$ \\
\hline \multicolumn{6}{|c|}{$\begin{array}{l}\text { Data are presented as mean } \pm \text { SD otherwise stated. PFMT: Pelvic Floor Muscle Training; CST: Cough- } \\
\text { Suppression }\end{array}$} \\
\hline \multicolumn{6}{|c|}{$\begin{array}{l}\text { Therapy; } \mathrm{FEV}_{1} \text { : forced expiratory volume in one second; FVC: Forced vital capacity; GOLD: Global } \\
\text { Initiative for Chronic }\end{array}$} \\
\hline \multicolumn{6}{|c|}{$\begin{array}{l}\text { Obstructive Lung Disease; 6MWD; six-minute walk distance; CAT: COPD Assessment Test; ICIQ-UI SF: } \\
\text { International Consultation on Incontinence Questionnaire - Urinary Incontinence Short Form ; LCQ: } \\
\text { Leicester Cough Questionnaire; IQR: interquartile range. }\end{array}$} \\
\hline
\end{tabular}

\section{Table 2}

The correlation between ICIQ-UI SF and age, duration of UI, pelvic floor muscle contraction, functional exercise capacity and health status at baseline $(n=29)$

\begin{tabular}{|c|c|c|c|c|c|c|}
\hline Variables & 1 & 2 & 3 & 4 & 5 & 6 \\
\hline 1. ICIQ-UI SF total score & 1.00 & & & & & \\
\hline 2. Age & -.22 & 1.00 & & & & \\
\hline 3. UI duration & $.59^{* *}$ & .19 & 1.00 & & & \\
\hline 4. ICS scale & .01 & -.17 & 0.06 & 1.00 & & \\
\hline 5. 6MWD & -.18 & $-.52 \star \star$ & -.20 & .17 & 1.00 & \\
\hline 6. CAT & .11 & .35 & .18 & .35 & $-.38 *$ & 1.00 \\
\hline \multicolumn{7}{|c|}{$\begin{array}{l}{ }^{\star \star} \text { Correlation is significant at the } 0.01 \text { level (2-tailed), }{ }^{*} \text { Correlation is significant at the } 0.05 \text { level }(2- \\
\text { tailed) }\end{array}$} \\
\hline \multicolumn{7}{|c|}{$\begin{array}{l}\text { ICIQ-UI SF: International Consultation on Incontinence Questionnaire - Urinary Incontinence Short } \\
\text { Form; UI: Urinary incontinence; ICS scale: International Continence Society scale for evaluation of } \\
\text { voluntary pelvic floor muscle contraction; 6MWD; six-minute walk distance; CAT: COPD assessment } \\
\text { test. }\end{array}$} \\
\hline
\end{tabular}

\section{Changes in UI and activity levels from baseline to post- intervention}

The PFMT group and control group women had a statistically and clinically significant mean reduction of 3.4 points and 3.0 points, respectively on the ICIQ-UI SF score (Table 3), whereas the reduction in the CST group was 0.5 points only $(p=0.46)$ (Fig. 2$)$. The physical activity level was low in all three groups at baseline (Table 3 ) and no significant change was seen at post-intervention. 
Table 3

Mean changes in for the interventions and control groups, post- minus pre-test

$\begin{array}{lllll}\text { Variables } & \text { Completers } & \text { PFMT group } & \text { CST group } & \text { Control group } \\ & \mathrm{N}=29 & \mathrm{~N}=7 & \mathrm{~N}=12 & \mathrm{~N}=10\end{array}$

\section{ICIQ-UI total score}

$\begin{array}{lllll}\text { Baseline } & 9.1 \pm 4.3 & 8.9 \pm 4.3 & 7.3 \pm 4.6 & 11.4 \pm 2.8 \\ \text { Mean Change } & -2.1 \pm 3.1^{\star \star} & -3.4 \pm 3.2^{*} & -0.5 \pm 2.3 & -3.0 \pm 3.4^{\star} \\ \text { missing } & 0 & 0 & 0 & 0\end{array}$

6MWD

$\begin{array}{lllll}\text { Baseline } & 381 \pm 121 & 382 \pm 97 & 375 \pm 160 & 388 \pm 88 \\ \text { Mean Change } & -7 \pm 0 & 12 \pm 46 & -3 \pm 60 & -38 \pm 89 \\ \text { missing } & 2 & 0 & 1 & 1\end{array}$

\section{Steps/day}

\begin{tabular}{lllll} 
Baseline & $3416 \pm 2762$ & $3565 \pm 1732$ & $2439 \pm 2460$ & $4449 \pm 3434$ \\
Mean Change & $267 \pm 1048$ & $218 \pm 557$ & $-93 \pm 1001$ & $1053 \pm 1514$ \\
\hline missing & 16 & 3 & 6 & 7
\end{tabular}

CAT total score

$\begin{array}{lllll}\text { Baseline } & 23.1 \pm 6.4 & 24.1 \pm 5.7 & 20.6 \pm 6.8 & 25.5 \pm 5.7 \\ \text { Mean Change } & 0.2 \pm 6.1 & -2.1 \pm 6.3 & 3.4 \pm 4.9^{\star} & -1.6 \pm 6.3 \\ \text { missing } & 1 & 0 & 2 & 0\end{array}$

LCQ total median ${ }^{1}$

\begin{tabular}{lllll|} 
Baseline & 16 & 15 & 15 & 17 \\
Change (median) & 0 & 0 & 1.0 & -0.5 \\
missing & 2 & 0 & 2 & 0 \\
\hline ICS baseline & & & & 4 \\
Weak, $\mathrm{n}(\%)$ & 16 & 5 & 7 & 3 \\
\hline Normal, $\mathrm{n}(\%)$ & 8 & 2 & 3 &
\end{tabular}

Data are presented as mean \pm SD otherwise stated. ${ }^{*}=p<0.01 ;{ }^{*} p=<0.05$; PFMT: pelvic floor muscle training; CST: Cough-Suppression Therapy; ICIQ-UI SF: International Consultation on Incontinence Questionnaire - Urinary Incontinence Short Form; 6MWD; six-minute walk distance; CAT: COPS Assessment Test; LCQ: Leicester Cough Questionnaire; ICS: International Continence Society. 


\begin{tabular}{|c|c|c|c|c|}
\hline Variables & $\begin{array}{l}\text { Completers } \\
\mathrm{N}=29\end{array}$ & $\begin{array}{l}\text { PFMT group } \\
\mathrm{N}=7\end{array}$ & $\begin{array}{l}\text { CST group } \\
N=12\end{array}$ & $\begin{array}{l}\text { Control group } \\
N=10\end{array}$ \\
\hline Spastic, n (\%) & 5 & 0 & 2 & 3 \\
\hline missing & 0 & 0 & 0 & 0 \\
\hline \multicolumn{5}{|c|}{ ICS post-intervention } \\
\hline Weak, n (\%) & 7 & 2 & 3 & 2 \\
\hline Normal, n (\%) & 11 & 5 & 3 & 3 \\
\hline Spastic, n (\%) & 4 & 0 & 2 & 2 \\
\hline missing & 7 & 0 & 4 & 3 \\
\hline \multicolumn{5}{|c|}{$\begin{array}{l}\text { Data are presented as mean } \pm \text { SD otherwise stated. }{ }^{* *}=p<0.01 ;{ }^{*} \mathrm{p}=<0.05 \text {; PFMT: pelvic floor muscl } \\
\text { training; CST: Cough-Suppression Therapy; ICIQ-UI SF: International Consultation on Incontinence } \\
\text { Questionnaire- Urinary Incontinence Short Form; } 6 \mathrm{MWD} \text {; six-minute walk distance; CAT: COPS } \\
\text { Assessment Test; LCQ: Leicester Cough Questionnaire; ICS: International Continence Society. }\end{array}$} \\
\hline
\end{tabular}

\section{Discussion}

This randomised controlled study explored the effect of PFMT and CST on treating UI in women with COPD. Due to difficulties with recruitment, such as practical issues regarding travelling distance, lack of interest, poor state of health and high number of comorbidities, we did not reach the number of participants required in each study group as shown in our sample size estimation. Our results demonstrated a trend of reduced UI symptoms amongst women in the PFMT and control groups and no change in the CST group. However, due to insufficient statistical power, the results must be considered with caution.

During the three year study period, a number of measures were attempted to recruit participants, such as visiting COPD exercise groups to inform patients and clinicians about the study, advertising via social media, and making telephone calls to potential participants to encourage them to participate. In addition, the recruiting phase of the study was extended and a second study centre in a separate Norwegian health region was included in the study. However, it was difficult to engage patients despite many of them reporting problems with UI. Despite a high number of patients in both health regions were invited to the study, our study did not reach the required sample size. The assessment of VPFMC included an internal examination (vaginal palpation) which may have deterred potential participants from being recruited to the study, due to embarrassment or discomfort. Despite this being a potential barrier to recruitment, assessment of the participants' ability to perform VPFMC prior to PFMT is advised as it is unlikely that women who are unable to perform VPFMC at baseline will benefit fully from PFMT alone. Women unable to contract their PFM at baseline may potentially require supplemental treatment such as electrical stimulation in order to improve their PFM strength and reduce UI symptoms if allocated to the PFMT intervention group (38). 
To our knowledge, this is the first study that has investigated the use of PFMT alone in this patient group. Our findings suggest that PFMT may be an effective treatment for UI in women with COPD. Surprisingly, a reduction in UI symptoms was also observed in the control group. Due to ethical reasons, all recruited women were instructed in how to perform a VPFMC at baseline assessment and were informed of the benefits of PFMT. Therefore, a plausible explanation may be that women in the control group started to perform PFMT on their own initiative following randomisation. Performing PFMT in groups led by a physiotherapist has been found to be more effective than unsupervised home training (39) and therefore one would still have expected a greater improvement amongst the participants who followed a structured program supervised by a specialised physiotherapist. However, as this is only a small study, larger numbers would be required to explore this further.

Ul severity was significantly correlated with UI duration, but we found no other correlations between UI and age, lung function, parity, cough symptoms, VPFMC, 6MWD or health status. The participants were representative for the COPD population in terms of age and disease severity. Despite this, they presented with severe UI symptoms and approximately half had weak VPFMC when measured with vaginal palpation at study inclusion. This was somewhat unexpected as the presumption was that higher grades of Ul severity would correlate with COPD severity, chronic cough symptoms, weak PFM, poorer heath status and reduced physical activity levels. Studies have previously shown that people with COPD commonly have peripheral muscle weakness as compared to age-matched controls (40) and it is therefore possible that similar muscle atrophy is present in the PFM affecting the ability to perform an effective VPFMC. However, despite the majority of participants having reduced VPFMC at baseline, these women had surprisingly normal PFM strength compared to the general female population with UI, especially when considering their high levels of inactivity and presumed peripheral muscle weakness. VPFMC function was measured in a resting, supine position and not during activities such as walking, jumping or coughing which place extra pressure on the pelvic floor. Despite the participants being able to contract the PFM in a resting state, it is possible that they are not able to, or forget to, contract the PFM during coughing, sneezing or breathlessness. PFMT aims to improve an automatic co-contraction of the PFM to counteract any increase in abdominal pressure or the increase from ground reaction force, and previous studies suggest that purely teaching patients to contract the PFM during coughing (known as "the knack") reduces UI by up to $70 \%$ (41). However, our results suggest that the presence of UI in women with COPD is multifactorial. It is possible that these patients adjust their lifestyle to cope with UI or that UI does not affect them negatively compared to other more bothersome symptoms, such as dyspnoea. Despite the mean airflow obstruction representing moderate COPD, study participants reported high symptom burden on the CAT, suggesting a great deal of challenges related to their COPD. Our findings therefore indicate that $\mathrm{UI}$ affects women with COPD regardless of disease severity such as it is probably wise to screen all women with COPD for the presence of $\mathrm{Ul}$, irrespective of other factors.

UI has previously been demonstrated to be a barrier for participating in physical activity in general female populations (15). Therefore, the combination of inactivity in COPD due to dyspnoea and UI may result in a double risk factor for reduced compliance to physical activity. Despite the study participants being generally very inactive, the SenseWear activity monitor did not demonstrate a correlation between daily 
physical activity and any other variables including $\mathrm{UI}$ severity and lung function. However, due to the low response rate, and a lack of case-controls, it is difficult to conclude whether this convenience sample of COPD women with coexisting $\mathrm{UI}$ is representative for the population. Our participants may not represent women with mild or severe COPD and $\mathrm{UI}$ as they are less likely to attend pulmonary rehabilitation or physiotherapy clinics and are thus not available for recruitment.

\section{Limitations}

Due to the small sample size and relatively high dropout rate, it is difficult to conclude the effectiveness of the interventions, as previously discussed. Furthermore, CST is not a well-documented or standardised treatment and this may have resulted in less than optimal results in in the CST group. Future qualitative studies to identify the barriers to recruitment in this patient group, such as practical issues with transport, beliefs about effect of treatment, and reducing embarrassment about the somewhat taboo issue of UI, may provide an insight on how UI affects women with COPD, including those unable to participate in a research study. Studies should also include women with milder COPD and UI where the potential to prevent the development of UI may be greater. Despite this, our results may still lead to increased awareness regarding $\mathrm{UI}$ in patients with COPD, as well as giving an indication to which interventions may be effective. This in turn may result in better patient care by extending the knowledge base for prevention, diagnostics, and treatment of Ul amongst patients with COPD. Additionally, further research is required to explore the relationship between VPFMC and general strength in this population.

\section{Conclusion}

Due to the low number of available participants and recruitment difficulties, including practical issues such as travel distance, lack of interest, poor state of health and high number of comorbidities, our results are inconclusive. However, our results support previous evidence that PFMT is the primary choice of treatment for $\mathrm{UI}$ in the general female population, as our findings suggest that PFMT may be an effective treatment for women with COPD and coexisting UI. Increased knowledge about COPD and coexisting UI may lead to improved routines for the assessment, prevention and treatment of $\mathrm{Ul}$ amongst this population, as well as increasing awareness and reducing taboos around the subject of UI among COPD patients. Routine screening for symptoms of $\mathrm{Ul}$ amongst people with $\mathrm{UI}$ may provide the opportunity to identify, educate and treat these patients, which may lead to reduced symptom burden and improved quality of life. More research exploring the association between COPD and coexisting $\mathrm{Ul}$ is needed, as well as larger studies investigating barriers to recruitment and treatment options for reducing $\mathrm{UI}$ among COPD patients.

\section{Abbreviations}

UI Urinary incontinence

COPD Chronic obstructive pulmonary disease

Page 13/21 
PFMT Pelvic floor muscle training

CST Cough-suppression therapy

PFM Pelvic floor muscles

HRQL Health-related quality of life

SUI Stress urinary incontinence

GOLD Global Initiative for Chronic Obstructive Lung Disease

FEV $_{1}$ Forced expiratory volume in 1 second

FVC Forced vital capacity

VPFMC Voluntary pelvic floor muscle contraction

6MWT Six minute walk test

LCQ Leicester cough questionnaire

CAT COPD Assessment test

ICS International Continence Society score

RCT Randomised controlled trial

SD Standard deviation

6MWD Six minute walk distance

PROMS Patient-reported outcome measures

\section{Declarations}

\section{Ethics approval and consent to participate}

The choice of the study design and methods are based on a solid rationale and international recommendations. Patients were informed about the study including the design, examinations, intervention, and anticipated benefits. Written informed consent was obtained from all participants prior to clinical procedures. Patients were enrolled by the project leader, and written informed consent was gathered at baseline. Patients who declined participation were managed according to the best current practice. Participants were informed about their right to withdraw from the study (according to the Helsinki declaration). The study is registered in Clinical Trials (NCT02614105). The protocol, including the 
patient information and consent form, is approved by the Regional Committee for Medical and Health Research Ethics (REK 2015/1326).

\section{Consent for publication}

Not applicable

\section{Availability of data and materials}

The datasets used and/or analysed during the current study are available from the corresponding author on reasonable request.

\section{Competing interests}

The authors declare that they have no conflict of interest.

\section{Funding}

This work was supported by the Østfold Hospital Trust under Grant AB3342. The role of the funding body was to contribute and support the design of the study, the collection, analysis, and interpretation of data, and two authors from ØНT were involved in writing the manuscript.

\section{Authors contributions}

SHP: Participated in planning and conduction of the study, interpretation of the results, and writing of the manuscript.

BF: Performed the statistical analysis, participated in the interpretation of the results, and writing of the manuscript.

MAS: Participated in planning of study, interpretation of the results, and writing of the manuscript.

SNS: Participated in planning and conduction of study, interpretation of the results, and writing of the manuscript.

$\mathrm{HHJ}$ : Participated in planning and conduction of study, interpretation of the results, and writing of the manuscript.

All authors read and approved the final manuscript.

\section{Acknowledgements}

The authors wish to thank all the women who participated in the study, and the physiotherapists who contributed to the conduction of the study, especially Karen Thomas, Inger Storrøseter, Clara Karoliussen, Julia Trevor, Linda Sørby, Hilde Thorsen and Mats Westerfjell Grensemo. In addition, many thanks to Eivind Hasvik for his contribution with graphics and to Hanne Fjäll Larssen for performing the lung function tests. 


\section{References}

1. Hannestad YS, Rortveit G, Sandvik H, Hunskaar S. A community-based epidemiological survey of female urinary incontinence: the Norwegian EPINCONT study. Epidemiology of Incontinence in the County of Nord-Trondelag. Journal of clinical epidemiology. 2000;53(11):1150-7.

2. Chiarelli P, Brown WJ. Leaking urine in Australian women: prevalence and associated conditions. Women \& health. 1999;29(1):1-13.

3. Woodley SJ, Boyle R, Cody JD, Morkved S, Hay-Smith EJC. Pelvic floor muscle training for prevention and treatment of urinary and faecal incontinence in antenatal and postnatal women. The Cochrane database of systematic reviews. 2017;12:Cd007471.

4. Dumoulin C, Hay-Smith J. Pelvic floor muscle training versus no treatment, or inactive control treatments, for urinary incontinence in women. The Cochrane database of systematic reviews. 2010(1):Cd005654.

5. Haylen BT, de Ridder D, Freeman RM, Swift SE, Berghmans B, Lee J, et al. An International Urogynecological Association (IUGA)/International Continence Society (ICS) joint report on the terminology for female pelvic floor dysfunction. Neurourology and urodynamics. 2010;29(1):4-20.

6. Battaglia S, Benfante A, Principe S, Basile L, Scichilone N. Urinary Incontinence in Chronic Obstructive Pulmonary Disease: A Common Co-morbidity or a Typical Adverse Effect? Drugs \& aging. 2019;36(9):799-806.

7. Newman DK. In men and women with COPD the presence of urinary incontinence is associated with poorer quality of life. Evidence-based nursing. 2014;17(1):22-3.

8. Global Strategy for the Diagnois. Management, and Prevention of Chronic Obstructive Pulmonary Disease: 2020 Report 2020 [Available from: https://goldcopd.org/wpcontent/uploads/2019/12/GOLD-2020-FINAL-ver1.2-03Dec19_WMV.pdf.

9. Hrisanfow $E$, Hagglund $D$. The prevalence of urinary incontinence among women and men with chronic obstructive pulmonary disease in Sweden. Journal of clinical nursing. 2011;20(13-14):1895-905.

10. Aigon A, Billecocq S. [Prevalence and impact on quality of life of urinary incontinence in an adult population with chronic obstructive pulmonary diseases, literature review]. Progres en urologie : journal de I'Association francaise d'urologie et de la Societe francaise d'urologie. 2018;28(17):962-72.

11. Hrisanfow E, Hagglund D. Impact of cough and urinary incontinence on quality of life in women and men with chronic obstructive pulmonary disease. Journal of clinical nursing. 2013;22(1-2):97-105.

12. Debus G, Kastner R. Psychosomatic Aspects of Urinary Incontinence in Women. Geburtshilfe und Frauenheilkunde. 2015;75(2):165-9. 
13. Kwak Y, Kwon H, Kim Y. Health-related quality of life and mental health in older women with urinary incontinence. Aging \& mental health. 2015:1-8.

14. Senra C, Pereira MG. Quality of life in women with urinary incontinence. Revista da Associacao Medica Brasileira (1992). 2015;61(2):178-83.

15. Nygaard I, Girts T, Fultz NH, Kinchen K, Pohl G, Sternfeld B. Is urinary incontinence a barrier to exercise in women? Obstetrics and gynecology. 2005;106(2):307-14.

16. Troosters T, Demeyer H. Physical Inactivity as a Missing Link in Understanding the Progression of Chronic Obstructive Pulmonary Disease. American journal of respiratory and critical care medicine. 2015;192(3):267-9.

17. Troosters T, Sciurba F, Battaglia S, Langer D, Valluri SR, Martino L, et al. Physical inactivity in patients with COPD, a controlled multi-center pilot-study. Respiratory medicine. 2010;104(7):1005-11.

18. Watz H, Pitta F, Rochester CL, Garcia-Aymerich J, ZuWallack R, Troosters T, et al. An official European Respiratory Society statement on physical activity in COPD. The European respiratory journal. 2014;44(6):1521-37.

19. Waschki B, Kirsten A, Holz O, Muller KC, Meyer T, Watz H, et al. Physical activity is the strongest predictor of all-cause mortality in patients with COPD: a prospective cohort study. Chest. 2011;140(2):331-42.

20. Button BM, Holland AE, Sherburn MS, Chase J, Wilson JW, Burge AT. Prevalence, impact and specialised treatment of urinary incontinence in women with chronic lung disease. Physiotherapy. 2019;105(1):114-9.

21. Chamberlain S, Garrod R, Birring SS. Cough suppression therapy: does it work? Pulmonary pharmacology \& therapeutics. 2013;26(5):524-7.

22. Vogelmeier CF, Criner GJ, Martinez FJ, Anzueto A, Barnes PJ, Bourbeau J, et al. Global Strategy for the Diagnosis, Management, and Prevention of Chronic Obstructive Lung Disease 2017 Report: GOLD Executive Summary. Eur Respir J. 2017;49(3).

23. Kraemer WJ, Adams K, Cafarelli E, Dudley GA, Dooly C, Feigenbaum MS, et al. American College of Sports Medicine position stand. Progression models in resistance training for healthy adults. Medicine and science in sports and exercise. 2002;34(2):364-80.

24. Bø K. Physiotherapy management of urinary incontinence in females. J Physiother. 2020;66(3):147-54.

25. Morkved S, Bo K, Fjortoft T. Effect of adding biofeedback to pelvic floor muscle training to treat urodynamic stress incontinence. Obstetrics and gynecology. 2002;100(4):730-9. 
26. Bo K. [Pelvic floor muscle exercise and urinary incontinence--train yourself continent!]. Tidsskrift for den Norske laegeforening : tidsskrift for praktisk medicin, ny raekke. 2000;120(29):3583-9.

27. Avery K, Donovan J, Peters TJ, Shaw C, Gotoh M, Abrams P. ICIQ: a brief and robust measure for evaluating the symptoms and impact of urinary incontinence. Neurourology and urodynamics. 2004;23(4):322-30.

28. Sirls LT, Tennstedt S, Brubaker L, Kim HY, Nygaard I, Rahn DD, et al. The minimum important difference for the International Consultation on Incontinence Questionnaire-Urinary Incontinence Short Form in women with stress urinary incontinence. Neurourology and urodynamics. 2015;34(2):183-7.

29. Vooijs M, Alpay LL, Snoeck-Stroband JB, Beerthuizen T, Siemonsma PC, Abbink JJ, et al. Validity and usability of low-cost accelerometers for internet-based self-monitoring of physical activity in patients with chronic obstructive pulmonary disease. Interactive journal of medical research. 2014;3(4):e14.

30. Farooqi N, Slinde F, Haglin L, Sandstrom T. Validation of SenseWear Armband and ActiHeart monitors for assessments of daily energy expenditure in free-living women with chronic obstructive pulmonary disease. Physiological reports. 2013;1(6):e00150.

31. Singh SJ, Puhan MA, Andrianopoulos V, Hernandes NA, Mitchell KE, Hill CJ, et al. An official systematic review of the European Respiratory Society/American Thoracic Society: measurement properties of field walking tests in chronic respiratory disease. The European respiratory journal. 2014;44(6):1447-78.

32. Holland AE, Spruit MA, Troosters T, Puhan MA, Pepin V, Saey D, et al. An official European Respiratory Society/American Thoracic Society technical standard: field walking tests in chronic respiratory disease. The European respiratory journal. 2014;44(6):1428-46.

33. Berkhof FF, Boom LN, ten Hertog NE, Uil SM, Kerstjens HA, van den Berg JW. The validity and precision of the Leicester Cough Questionnaire in COPD patients with chronic cough. Health and quality of life outcomes. 2012;10:4.

34. Birring SS, Prudon B, Carr AJ, Singh SJ, Morgan MD, Pavord ID. Development of a symptom specific health status measure for patients with chronic cough: Leicester Cough Questionnaire (LCQ). Thorax. 2003;58(4):339-43.

35. Ringbaek T, Martinez G, Lange P. A comparison of the assessment of quality of life with CAT, CCQ, and SGRQ in COPD patients participating in pulmonary rehabilitation. Copd. 2012;9(1):12-5.

36. Messelink B, Benson T, Berghmans B, Bo K, Corcos J, Fowler C, et al. Standardization of terminology of pelvic floor muscle function and dysfunction: report from the pelvic floor clinical assessment group of the International Continence Society. Neurourology and urodynamics. 2005;24(4):374-80. 
37. Laszlo G. European standards for lung function testing: 1993 update. Thorax. 1993;48(9):873-6.

38. Dumoulin C, Cacciari LP, Hay-Smith EJC. Pelvic floor muscle training versus no treatment, or inactive control treatments, for urinary incontinence in women. The Cochrane database of systematic reviews. 2018;10(10):Cd005654.

39. Paiva LL, Ferla L, Darski C, Catarino BM, Ramos JGL. Pelvic floor muscle training in groups versus individual or home treatment of women with urinary incontinence: systematic review and metaanalysis. International Urogynecology Journal. 2017;28(3):351-9.

40. Bernard S, LeBlanc P, Whittom F, Carrier G, Jobin J, Belleau R, et al. Peripheral muscle weakness in patients with chronic obstructive pulmonary disease. Am J Respir Crit Care Med. 1998;158(2):629-34.

41. Miller JM, Perucchini D, Carchidi LT, DeLancey JO, Ashton-Miller J. Pelvic floor muscle contraction during a cough and decreased vesical neck mobility. Obstet Gynecol. 2001;97(2):255-60.

\section{Figures}




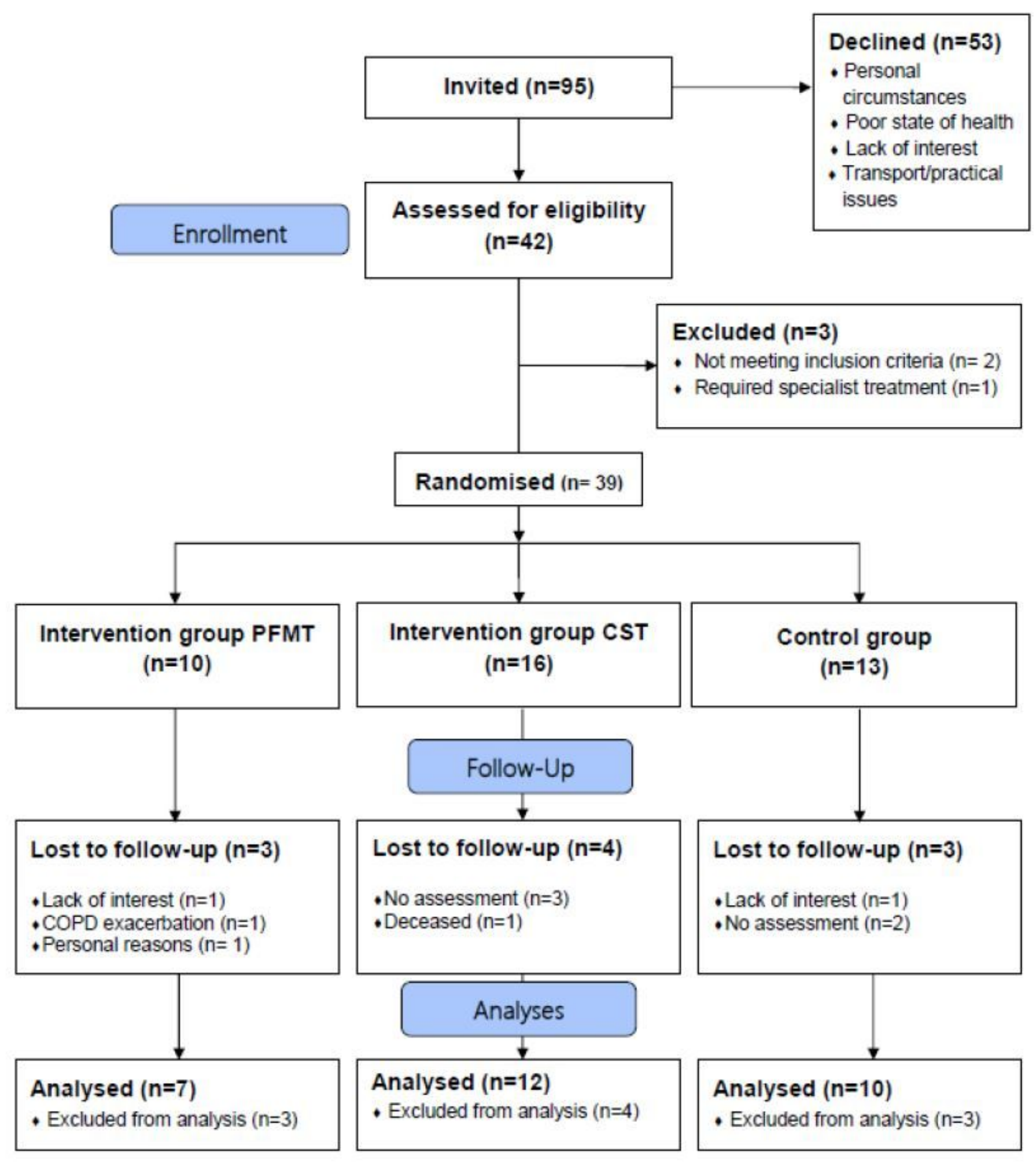

Figure 1

Flow chart of the recruitment and inclusion process through each stage of the randomised controlled trial 


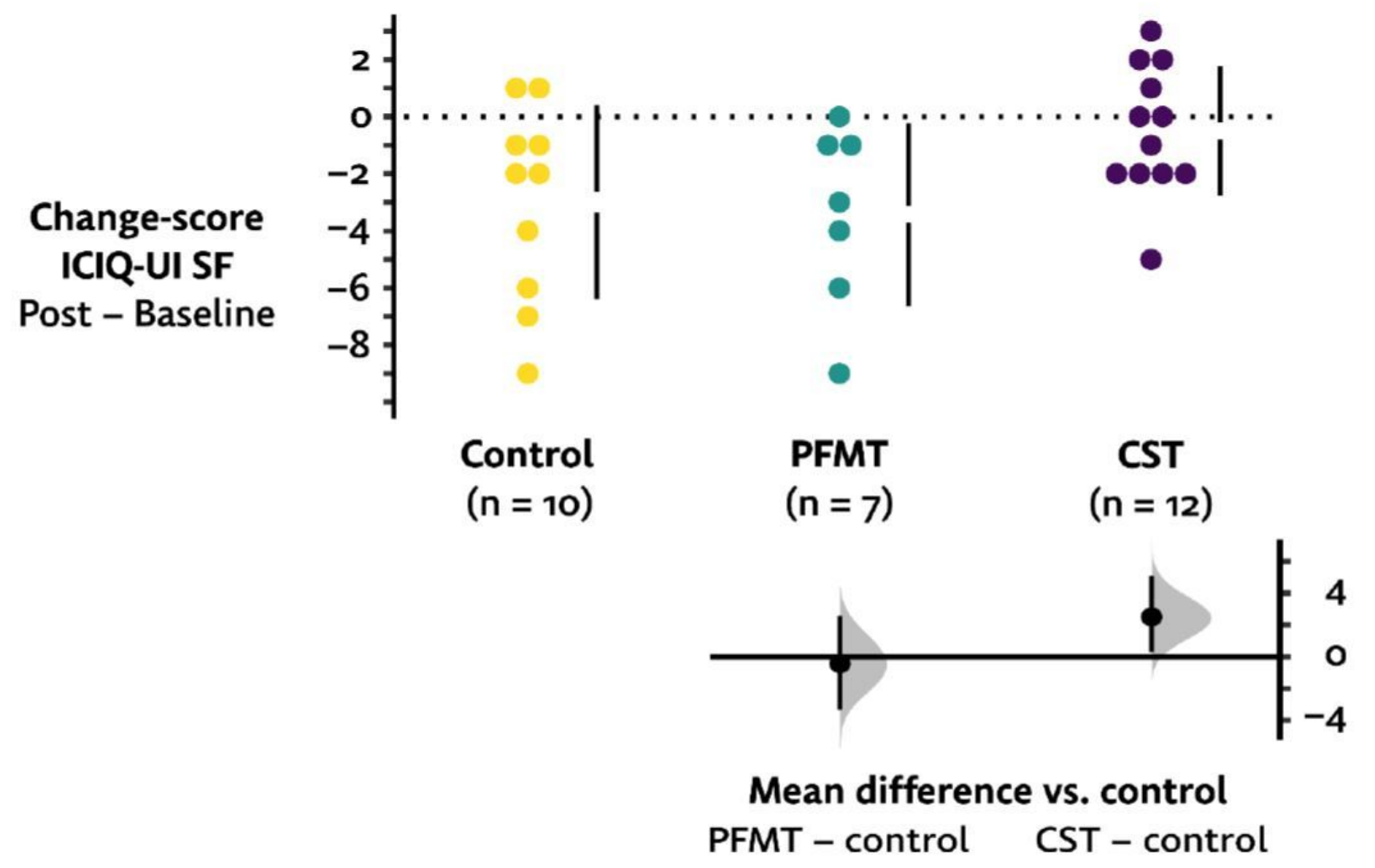

Figure 2

Change in ICIQ-UI SF scores from baseline to post intervention ( $n=29)$. Cumming shared-control estimation plot showing the change scores of the ICIQ-UI SF from baseline to post intervention on the upper axis. Each individual's change is shown as white (control group), black (PFMT group) and grey (CST group) dots and the mean (SD) group change is indicated with the vertical error bars. On the bottom axis, the mean difference compared to the shared control with $95 \% \mathrm{Cl}$ is plotted on a floating axis with a bootstrap sampling distribution in grey: PFMT to control $-0.4(-3.3,2.6)$, CST to control $2.5(0.3,5.1)$. 